\title{
ISSO SIM É COMIDA DE MADAME: UM ESTUDO SOBRE A RELAÇÃO ENTRE PRÁTICAS ALIMENTARES E MOBILIDADE SOCIAL ASCENDENTE
}

\author{
NOW THAT'S MADAME FOOD: \\ A STUDY ON THE RELATIONSHIP BETWEEN FEEDING \\ PRACTICES AND UPWARD SOCIAL MOBILITY
}

\author{
Juliana Abonizio* \\ Maria Luisa Jimenez-Jimenez ${ }^{* *}$
}

\section{Introdução ${ }^{1}$}

A alimentação se situa entre o biológico e o cultural e, assim, discutir esse tema põe em pauta questões centrais da disciplina antropológica (ROMANELLI,2006). 0 consumo alimentar baseia-se em uma série de saberes e fazeres que são construídos historicamente, porém, atualmente há um questionamento do conceito de hábitos alimentares sobretudo ligado a matrizes cul- turais referentes a tradições nacionais, pois, segundo Livia Barbosa (2007), tal conceito traz como pressuposto a existência de um padrão repetitivo de práticas e representações. Segundo a autora, essa hipótese é questionada por alguns pesquisadores do tema que perceberam a existência de uma heterogeneidade e fragmentação que não combinariam com a ideia de homogeneidade e permanência implícitas no conceito. Já outros autores veem essa pressuposta frag-

\footnotetext{
* Doutora em Sociologia pela Universidade Estadual Paulista (UNESP). Docente do Programa de Pós-Graduação em Estudos de Cultura Contemporânea da Universidade Federal de Mato Grosso - ECCO- UFMT (Cuiabá/MT/BR). abonizio.juliana@gmail.com

** Doutoranda em Estudos de Cultura Contemporânea pela Universidade Federal de Mato Grosso - ECCO-UFMT (Cuiabá/MT/BR).malujijimenez@hotmail.com

1. Esta reflexão teve uma versão preliminar apresentada no VII Encontro Nacional de Estudos de Consumo em 2014. Disponível em: ABONIZIO, JIMENEZ-JIMENEZ, 2014.É parte de uma pesquisa maior intitulada 0 que se põe à mesa: hábitos alimentares e fronteiras sociais em Cuiabá-MT, realizada na Universidade Federal de Mato Grosso. Parte dessa investigação, principalmente a discussão teórica, foi realizada no Instituto de Ciências Sociais da Universidade de Lisboa, no qual a primeira autora atuou como investigadora visitante entre os meses de setembro e dezembro de 2012, sob a supervisão do doutor José Manuel Sobral.
} 
mentação dos hábitos alimentares como uma desestruturação da alimentação causada por interesses econômicos. Por fim, há também o questionamento sobre a alimentação atual que não seria baseada em hábitos fundados em tradições, mas uma alimentação tendente à homogeneidade no sentido de pasteurização causada pela perda das identidades relativas à cozinha e subjugadas pela globalização que impõe ao mundo os mesmos padrões de fastfood.

Diante desse quadro, o objetivo deste artigo é ver como, nas biografias individuais, determinados hábitos alimentares são adotados e abandonados considerando a pertinência a determinados grupos sociais. Sabendo que a comida comunica e classifica grupos, subgrupos e estamentos sociais nas sociedades complexas, consideramos que a mudança de lugar social implica em uma mudança nos hábitos alimentares e aquilo que eles significam. Especificamente, nosso objetivo é ver como a mobilidade social ascendente favorece transformações nas dietas de pessoas concretas e como tais dietas se articulam às suas biografias.

Para Cascudo (2004, p.41), o "alimento é um fixador psicológico no plano emocional" e "comer certos pratos é ligar-se ao local do produto". 0 autor refere-se à nação ao falar de lugar, mas alargamos sua afirmação e percebemos que também é válida para o local social. Assim, comer certos pratos ligam pessoas às classes que pertencem ou nas quais desejam criar raízes.

Como exemplo, podemos destacar o significado da carne para o grupo estudado por Alba Zaluar (1985). Na análise da autora, a carne é indicador de prestígio e considerada "comida forte", por isso tem muita importância na dieta dos trabalhadores que chegam mesmo a considerar "passar fome" fazer uma dieta sem carne e sem arroz e feijão. Magalhães (1995), citando inclusive as pesquisas de Zaluar, procura compreender o que significa alimentação para as camadas populares que, em geral, preferem comidas consideradas fortes e se identificam com esse segmento.

Para Magalhães (1995), as “classes de baixa renda” se reconhecem como grupo social quando assumem padrões próprios. Esses padrões englobam as noções de sua posição dentro da estrutura social, tanto negativos (os limites econômicos, a situação de crise financeira, etc.) como positivos (a noção de que os "pobres" é que comem melhor, que sabem comer, em contraposição aos "ricos" que só "comem besteiras"). Mas essencialmente, a identidade vem da diferenciação em relação aos outros grupos, sempre colocando um confronto, uma comparação entre eles.

A diferenciação entre os grupos dá-se em aspectos variados, dentre os quais destacamos o consumo, e, especificamente para esta análise, o consumo alimentar. Nesta esfera, as diferenças entre classes podem estar em vários elementos que compõem o sistema alimentar: ingredientes, modo de preparo, modo de servir, número de refeições, etc. As regras de conduta e etiqueta à mesa também reforçam as hierarquias entre classes e disseminam padrões, como Elias (1994) discute ao revelar o processo civilizador.

Contudo, as fronteiras que separam são as mesmas que aproximam e os hábitos alimentares são dinâmicos. Na verdade, pessoas e coisas se movem socialmente. As pessoas, ao mudarem seus lugares sociais, mudam seus hábitos alimentares, mas determinadas comidas também mudam sua posição. Assim, comidas antes consideradas símbolos de bom gosto e de classe alta, se popularizam e comidas, antes populares, são ressignificadas e adotadas pela alta cozinha. 
A sociedade contemporânea manifesta sua complexidade por inúmeras práticas dietéticas que variam de acordo com o poder aquisitivo, as crenças nutricionais, as concepções morais, dentre outros fatores. Além disso, os hábitos encontram-se menos enraizados e são transformados em pouco espaço de tempo, seja por influência de novas descobertas científicas, imperativos da moda, difusão de novas tecnologias que influenciam o preparo de alimentos, persuasão publicitária, etc. Dentre esses vários fatores, consideramos que a mobilidade social ascendente pode atuar na mudança de hábitos alimentares, tanto pelo acesso a determinados bens que antes eram impossibilitados pelos constrangimentos financeiros quanto pelas convenções de gosto que são influenciadas por intermediários culturais, pela moda e ainda pela nova socialização.

Em uma nova condição social resultante da mobilidade ascendente, o papel desempenhado por mulheres torna-se essencial, uma vez que, tradicionalmente, é a mulher responsável pela escolha do cardápio da família e agora passa a socializar com os demais membros a nova dieta e maneiras de fazer. Como afirma Jimenez-Jimenez (2016, p. 139) “A responsabilidade da casa, porém, e tudo que está ligado a ela continua com as mulheres, sejam elas patroas ou domésticas, visto que a sociedade cobra, como sinal de uma família próspera e feliz, uma casa organizada”.

Para Assunção (2008), as mulheres têm papel preponderante em suas famílias no que se refere à alimentação e aos cuidados. Assim, os discursos sobre as práticas alimentares atuam na defınição de papéis de gênero, apesar de assistirmos a vários questionamentos desses papéis e à emergência de novos arranjos familiares.

Considerando o exposto, para atingirmos o objetivo de compreender a passagem de um local social a outro, de um pertencimento de classe a outro, com base nas transformações do complexo que envolve os hábitos alimentares, entrevistamos mulheres, moradoras de Cuiabá-MT, que tiveram, em suas biografias, a experiência de mobilidade social ascendente.

A seleção das entrevistadas deu-se por meio de uma metodologia de conveniência e, em comum, todas consideraram ter tido um aumento no poder de consumo nos últimos anos. Inicialmente, para a realização das primeiras entrevistas, recorremos às conversas informais em estabelecimentos comerciais em um bairro considerado de classe média pela população local, frequentados individualmente por cada uma das autoras deste artigo. Ao explicitarmos as intenções da pesquisa, houve mulheres que indicaram suas amigas, inclusive algumas das que estavam ali, no mesmo local. Foram realizadas entrevistas após o fim das compras, ou ainda em locais combinados com as entrevistadas após agendamento de dia e horário que melhor lhes conviesse. Também entrevistamos pessoas indicadas por pesquisadores e estudantes do grupo de pesquisa que participamos. Não estabelecemos uma meta em número de entrevistas a serem realizadas, antes, através do andamento da pesquisa e da confrontação das entrevistas realizadas individualmente, percebemos a repetição de padrões que nos fez considerar já termos um número suficiente para atingir nosso objetivo que não tem, ressaltamos, finalidade quantitativa. Ao todo, entrevistamos 22 mulheres residentes em Cuiabá, sendo 16 negras, 4 brancas e 2 pardas. Da totalidade, 17 são cuiabanas, uma do interior do estado de Mato Grosso, 4 são de outros estados (Paraná, Maranhão, Rondônia e Goiás) e residem em Cuiabá há pelo menos 15 anos. A causa da 
ascensão social apresentada em suas histórias resulta do entrecruzamento de muitas variáveis que se sucedem e se sobrepõem no tempo, alternando sua importância para o local ocupado atualmente. As causas mais evocadas foram o casamento, diploma universitário, empreendimento, carreira do marido. A alternância ocorre quando, por exemplo, a ascensão se dá por meio do casamento que, por sua vez, possibilitou o estudo e este possibilitou uma inserção qualificada no mercado de trabalho levando a uma ascensão ainda maior. Com este exemplo, destacamos a fluidez e o caráter processual e pouco estagnado dos muitos lugares sociais existentes na percepção das entrevistadas. Suas narrativas contam basicamente um processo de ascensão com muitos degraus e não a passagem de um status fixo a outro.

A partir da autoidentificação das mulheres como pessoas que ascenderam socialmente, nossa pergunta básica foi: Com sua ascensão social houve mudanças na sua alimentação? Descreva.

Todas as entrevistadas acreditavam estar vivendo uma mudança no pertencimento social-espacial, já que mudaram seu poder aquisitivo e, com isso, modificaram também o espaço de circulação na cidade, ajustando-se à cartografia dos pertencimentos sociais. A mudança de habitação do subúrbio para bairros com metro quadrado mais valorizado vem acompanhada da mudança nos pontos comerciais que frequentam (novos supermercados, salões de beleza, restaurantes, etc.), implicando em uma adaptação à nova comunidade vicinal e aos hábitos de consumo que a caracterizam. Focamos nossa atenção nas transformações referentes ao consumo alimentar e sua relação com o novo lugar social ocupado.

Nos discursos analisados, percebemos que a nova condição social é expressa na procura e consumo de determinados pratos, dietas e utensílios que asseguram o sentido do novo pertencimento fornecendo emocionalmente a certeza de fazer parte de um novo grupo social. Ao mesmo tempo, os novos hábitos atuam como ritual de afastamento das escolhas e dos acessos antigos que demarcavam a classe de origem. Por exemplo, nos discursos foi bastante recorrente o relato de um gradual afastamento do arroz e feijão como base do prato diário, assim como foi relatada a procura por novos cortes de carne classificados como mais nobres. Também notamos a crescente preocupação com a diminuição do consumo de alimentos gordurosos e a consequente procura por alimentos considerados saudáveis, incluindo orgânicos e os etiquetados como diet e light. Por fım, os discursos também apresentaram a introdução de pratos estrangeiros, receitas e ingredientes globalizados, introduzidos pela frequência a restaurantes e viagens de lazer que expressam novos conhecimentos adquiridos por meio dos hábitos de consumo.

\section{Comida do ponto de vista da cultura}

A alimentação compõe um sistema cultural que ultrapassa o fato nutricional intrínseco ao ato de se alimentar, e nesse sentido interessa aos estudos de cultura. A comida e tudo que a envolve - seleção, descarte, modos de preparo, regras de servir, interdições, etc. - podem ser pensados como um sistema de comunicação. Nessa linha, Amon e Menasche (2008) salientam a capacidade comunicativa da comida e sua faculdade de contar histórias, configurando um sistema de codificação e classificação do mundo. Douglas e Isherwood (2009), ao analisar o consumo do ponto de vista 
cultural, também ressaltam a sua faculdade de classificação e organização do mundo, fazendo parte do sistema cultural, mesmo aquele consumo que, em tese, serviria à necessidade física - como é o caso da comida que, junto com a bebida "não são menos portadores de significado do que a dança ou a poesia" (DOUGLAS; ISHERWOOD, 2009, p. 120). Tais significados estão presentes em "nossos hábitos cotidianos, que são compostos pelo que é tradicional e pelo que se constitui com novos hábitos" (BRAGA, 2004, p. 5).

0 gosto também está presente na formação de uma cultura alimentar, já que as experiências culturais podem afetar a maneira que os individuos classificam as preferências pelos sabores que conformam o gosto. Mintz (2001) revela que as propriedades visuais, de textura e aparência podem afetar as preferências alimentares, já que configuram aspectos de um simbolismo alimentar que influenciam as escolhas.

Bourdieu (1987) ressalta que os atores sociais se diferem pela maneira como usam os bens materiais e simbólicos de uma sociedade de acordo com o acesso a esses bens, dando sentido ao mundo social e apresenta, por meio do conceito de $h a-$ bitus, uma maneira de entender a ligação entre o gosto e o pertencimento a estratos sociais. Sem negar essa relação, salientamos que atualmente, segundo Lipovetsky (2008), o consumidor, por ele designado de hipermoderno, está mais voltado para uma satisfação pessoal do que interessado em distinção social e exibição de status. De modo similar, Campbell (2006), ao analisar o que caracteriza o consumo contemporâneo, percebe que tal consumo está influenciado pela ideia de uma soberania do gosto pessoal, esfera em que cada um é sua própria autoridade. Para esse autor, as muitas ofertas de consumo, em vez de levar o indivíduo à crise de identidade, pode auxiliar na solução dessa crise através do gosto construído pela experimentação.

Assim, vemos que as decisões de consumo são afetadas simultaneamente por locais sociais, matrizes culturais e gostos individuais. No entrecruzamento desses muitos fatores, tais decisões de consumo dão tanto um senso de identidade ao indivíduo quanto um sentimento de pertinência a certas configurações sociais.

Diante desse aporte teórico, nosso desafio é compreender como as mulheres entrevistadas dão sentido às suas vidas e às suas posições sociais a partir das mudanças em suas experiências de consumo alimentar e como essas experiências interatuam na percepção de si mesmas e em seu modo de se situar socialmente. Para tanto, precisamos antes refletir sobre a mobilidade social e suas configurações em nossa história recente.

\section{Consumo, gosto de classe e ascensão so- cial no Brasil}

Os estudos de consumo compõem um campo de pesquisa relativamente recente do ponto de vista das ciências sociais - que durante muito tempo fechou os olhos para temas afins, priorizando as análises sobre o trabalho - e têm uma lacuna acerca das camadas subalternas que, até os anos 90 do século XX, não eram vistas como consumidoras nem pelos produtores nem por estudiosos (BARBOSA; CAMPBELL, 2006).

Após a política econômica adotada nos anos 1990, os bens que eram acessíveis a grupos com maior poder aquisitivo passam a ser consumidos por camadas populares que passam a ser consideradas público alvo de uma série de novos produtos. Salientamos que pertencer a uma classe social está 
muito além de possuir determinados bens de consumo, mas o que se consome pode comunicar, e muito, sobre os consumidores (BARBOSA, 2006; CANCLINI, 2010). Por meio do consumo, os sujeitos transmitem mensagens de grupos socioculturais dos quais fazem parte. Nesse sentido, caberia analisarmos, não estritamente as classificações de classe em termos de rendimentos ou posses, mas também seus valores imateriais e o modo como ambos podem interatuar na prática de consumo alimentar que compõe um sistema complexo de classificações, de conhecimentos, símbolos e habilidades.

Para compreender a mobilidade social dos sujeitos e seu sentimento de pertença não bastaria ver o custo dos alimentos, mas a construção social do gosto que se manifesta na ação de consumir o alimento e/ou comida que entrecruza preferências individuais, memória afetiva e outros fatores que compõem este complexo.

Em nossa pesquisa, focamos as entrevistas em mulheres que ascenderam socialmente e, apesar de não adotarmos nenhum comparativo de nível de renda, podemos dizer que elas pertencem à classe que vem sendo genericamente chamada de "nova classe média" e sobre a qual repousam dissensos.

Alguns estudos apontam que essa nova classe social começou a ser citada nas mídias depois da pesquisa "Nova classe média", realizada pelo Centro de Políticas Sociais (CPS) da Fundação Getúlio Vargas (FGV), coordenada pelo economista Marcelo Neri (2008). A partir dessa publicação, muitos setores econômicos passaram a atentar à população mais pobre no país e suas relações com o consumo (YACCOUB, 2011).

A pesquisa citada focou a chamada "classe C" e, através de uma pesquisa quantitativa, demonstrou-se que o aumento do poder aquisitivo dos consumidores ali localizados fez com que sua posição na hierarquia socioeconômica ascendesse. Com essa nova posição, também se modificou sua denominação e, assim, esse grupo passou a ser designado por "nova classe média" (NERI, 2008). Hilaine Yaccoub questiona a denominação de Neri, pois os membros do que ele denomina classe média seriam os empregados das chamadas “classes médias urbanas", na definição de Gilberto Velho (VELHO, 1989, apud YACCOUB, 2011, p. 206) e assim legitimaria o discurso do governo que negaria a existência de pobreza e miséria no Brasil.

Sem a intenção de resolver o debate sobre as defınições do conceito de "classe social”, restringimos nosso objetivo na compreensão do sentimento de pertencer a uma classe ascendente na perspectiva de mulheres através do relato de suas experiências de consumo alimentar. Assim, cabe-nos decifrar quais foram as mudanças de consumo dessa camada que ascendeu economicamente, e como essas mudanças estão sendo percebidas e contadas pelos atores que se consideram em ascensão social, tendo em mente que essa classe emergente, com o nome que se queira dar, vive uma experiência social que está em processo e, portanto, sua análise está inacabada (OLIVEIRA-CRUZ, 2013).

Por essas razões, em vez de nos atermos ao conceito de classe, privilegiamos a percepção do próprio indivíduo, enquanto protagonista de sua posição socioeconômica. Sendo assim, as mulheres que entrevistamos fazem parte da camada média da população urbana de Cuiabá que se consideram em situação de ascensão social.

\section{0 afastamento do arroz e feijão e a mu- dança no valor da carne}

Ao estudar os hábitos alimentares dos brasileiros em 10 capitais com mais de um 
milhão de habitantes, Livia Barbosa (2007) declara que, considerando o almoço, 94\% dos inquiridos declararam comer arroz e feijão com alguma carne vermelha (69\%), galinha (42\%), salada (30\%), macarrão (24\%), verduras (22\%) e legumes (18\%). A autora ainda ressalta a presença do arroz acima dos 90\% em todos os grupos sociais, assim como ocorre com o feijão, que só fica abaixo de $90 \%$ entre os segmentos de renda A (85,7\%), em Curitiba (87,5\%) e Belém (82,6\%).

Há muito tempo que o feijão com farinha no Brasil, antes mesmo da incorporação do arroz, era a base do prato popular. 0 feijão é o que dava força para as camadas populares.

0 feijão era a refeição, o sustento, a força promotora da energia humana. Devia ser comido devagar, disposto o círculo de participantes, como para um cerimonial. Para o povo uma refeição sem feijão é simples ato de enganar a fome. Não de alimentar-se. (CASCUD0, 2004, p.441)

No entanto, os dados obtidos em nossas entrevistas apontam para nuances diferentes. Em um primeiro momento, vimos que os discursos afirmam um abandono, ou quase, do arroz com feijão, prato considerado próprio para quem faz serviços pesados e não próprio da camada social mais rica. Arroz e feijão é "prato de pedreiro", "prato de peão". Intrigadas com afırmações desse tipo, percebemos que, no decorrer das entrevistas, o afastamento do arroz com feijão era relativo à ingestão da própria entrevistada, muito embora o prato continuasse a ser servido na mesa da família. Em geral, os maridos comiam arroz e feijão, as empregadas domésticas comiam arroz e feijão, assim como os filhos, principalmente crianças e adolescentes do gênero masculino. As mulheres, na sua quase totalidade, demonstraram uma abstenção do arroz e feijão, sobretudo para não engordarem. "Eu não trabalho pesado, porque preciso de arroz e feijão? Fico com as misturas, as saladas. Arroz e feijão é só prá encher". Diante dos dados construídos, percebemos simultaneamente a presença do arroz e do feijão na escolha do menu, sobretudo do almoço, mas a sua ausência no prato da própria entrevistada. Já no jantar, o arroz e feijão dão lugar a um "lanche", um prato único, considerado, em geral, mais prático e menos calórico. 0 arroz e feijão são excluídos também dos momentos festivos ou quando se têm "visita", afınal, "ninguém vai convidar alguém prá almoçar e servir arroz e feijão, né?” Esses momentos são vistos como ocasião de exibição e de se comprovar a ascensão através do bom gosto.

"Comida de classe" - termo usado por uma das entrevistadas para designar algo fino, refinado, distintivo, portanto próprio das classes superiores -, definitivamente não tem como ingredientes o arroz com feijão. "Prato de classe", "prato fino" é outra coisa. Segundo Silvia, que disse ter nascido em uma família muito pobre da zona rural, fez universidade, hoje é professora e tem 37 anos: "Você não vê nas novelas, ou na casa de quem tem dinheiro, alguém comendo arroz e feijão, você vê comendo peixe, carnes finas, salada, nada de arroz e feijão". De modo semelhante, vemos outro relato:

Quando eu era criança, ainda não havia essas feiras, a gente nem via frutas como uva, pêssego, morango. Uma coisa que eu experimentei que minha mãe trouxe ${ }^{2}$ foi o iogurte, 
uma coisa fantástica. 0 que mudou? Hoje, eu conheço as frutas, compro coisas prontas, já não fico só no arroz e feijão, não é? Então fui aprendendo a fazer e também a comer né? Então, eu uso os talheres, aprendi o que pode misturar com o que, o que é considerado certo. (Gláucia, 43 anos, filha de empregada doméstica. Trabalhava como empregada doméstica. Atualmente é enfermeira tem três filhos e, por meio de um relacionamento afetivo, ascendeu socialmente)

A capacidade de importar novas práticas e gostos e também de construir um novo gosto para si mesmo vem junto com a construção de uma nova identidade, um produto da nova maneira de aparecer aos outros e de ser para si mesmo.

Vendo-se e desejando-se como pessoas refinadas, o arroz e o feijão passam a identificar a classe do passado, não a atual "Deus me livre voltar a comer feijão com farinha. Tem dia que era só isso que tinha no almoço".

É importante salientar que a mistura de pratos - destacada como característica brasileira segundo o estudo de Barbosa (2007) -, como arroz, feijão e macarrão com molho, comum no Nordeste, e arroz, feijão, estrogonofe e batata frita no Rio de Janeiro, é associada ao pouco conhecimento da origem dos diferentes pratos e do modo como são originalmente consumidos. Para a autora, só em estabelecimentos de alta gastronomia, encontraríamos uma mesma e única tradição culinária. Em nosso estudo, vemos que com a ascensão social e a frequência a restaurantes mais sofisticados, além do aumento no número de viagens nacionais e internacionais de lazer, as entrevistadas vão adquirindo novos conhecimentos das tradições culinárias e aplicam em suas vidas particulares, ainda que façam também adaptações.
Por exemplo, Tânia fala que era comum, em dia de fim de semana, fazer lasanha que era servida com arroz, feijão e batata palha. Ao perguntarmos sobre o modo de fazer a lasanha, ela descreveu que sua lasanha era montada com massas "dessas de supermercado", "molho de carne moída", presunto e queijo. A batata palha também era comprada. Hoje, chama seu prato simultaneamente de "gostoso" e de "mau gosto". Com risos, debocha de si mesma e afırma que "não faz sentido servir lasanha com arroz e feijão". Atualmente, quando faz lasanha, opta por massas compradas em casas específicas e a serve como prato único, também usa recheios alternativos como frango e ricota.

Ao dizer que "não faz sentido" determinada mistura de prato, a entrevistada percebe, ainda que intuitivamente, o caráter simbólico da comida e o universo de sentido que separa as classes sociais, uma vez que, em outro pertencimento social, em sua classe de origem, fazia todo o sentido servir daquela maneira. A reivindicação dessas mulheres, podemos aferir, não está só em adquirir posses, mas em inserir-se em um universo de sentido.

Se algumas coisas, como lasanha, arroz e feijão não “devem ser” misturadas, outras misturas passam a ser valorizadas.

Também gosto de comer salada e frutas junto no churrasco, gosto de assar abacaxi com canela, aprendi com minha patroa, a dona da loja. (Beatriz, 29 anos, mãe solteira de um filho, era vendedora de boutique no shopping, há dois anos é gerente da loja)

Assim, vemos que há diferenças que demarcam as fronteiras entre as classes. Com o acesso a novos padrões de gosto e estilo, certas misturas passam a ser aceitas, como o caso das frutas servidas com as comidas 
salgadas e outras misturas passam a sofrer interdições. Para os cuiabanos, apenas a banana da terra e o pequi poderiam ser misturados aos alimentos salgados, além do limão usado como tempero. No entanto, vemos esse padrão mudar. Outra coisa antes impensável era a salada ser a própria refeição.

Continuo não tendo frescura e admirando um bom prato de arroz e feijão, mas só raramente como isso, aprendi a comer outras coisas, a comer entradas, comer saladas de vários tipos. Às vezes, como só salada em uma refeição, antes isso era impensável, a gente comia o pratão de arroz e feijão com alguma mistura que tinha para poder trabalhar no pesado. Eu comia mais (risos) e era bem mais magra. Vai entender?!. (Virgínia 50 anos, filha de empregada doméstica. Casou-se muito jovem, mãe de três filhos, divorciada, e ascendeu socialmente tornandose professora)

Após a ascensão, nossas entrevistadas revelam apreço para saladas de acelga com abacaxi, alface com morangos, arroz com maçã verde e nozes, salada de rúcula com manga, risoto de manga, molho de manga ou maracujá para acompanhar o filé de frango. Enfım, novas misturas e novos padrões de gosto vão sendo aprendidos e também criados, uma vez que passam a inventar suas próprias receitas de acordo com os novos padrões aprendidos.

Se, como já dissemos baseando-nos nas reflexões de Cascudo (2004), o arroz e feijão eram considerados comida forte, vale salientar a importância da carne para as camadas populares, como destacou Zaluar (1985). A carne é vista como comida de sustança, uma refeição sem carne não dá força para o trabalhador. Essa classificação está presente no universo de nossas entrevista- das. A carne permanece valorizada, mas já não é por sua força, antes por seu requinte. Vemos a transformação no consumo explícita na opção por cortes de carne considerados mais nobres e menos gordurosos. Segundo Beatriz, já citada: "Quando eu não tinha quase dinheiro para comprar comida, comprava carne com osso, de segunda, agora não. Gosto de contra filé, picanha no churrasco, agora eu posso, faço questão de comprar só carne de primeira."

0 churrasco era feito aos fins de semana e continua sê-lo, o que efetivamente se modificou foram os cortes de carne e os acompanhamentos que vão se tornando mais refinados, segundo as próprias análises. A marca da cerveja que acompanha o churrasco também mudou com a ascensão social: "Que Sol o quê, Cristal, agora a gente bebe Heineken. Meu marido faz questão”. Além dos churrascos, o fim de semana é marcado pelo consumo de feijoada, contudo, essa também sofre alterações com a ascensão social.

Para Cascudo:

Não há casa por mais pobre que não tenha sua feijoada, nem há por mais rica que exclua de sua mesa esse prato por excelência, pelo qual pessoas de todas as classes manifestam um gosto igualmente pronunciado. (CASCUD0, 2004, p. 445-446).

Se o feijão era prato diário, a feijoada foi considerada como um prato a ser servido em dia especial. Os discursos revelam que todos apreciam uma "boa feijoada", porém deve ser mais magra que a feita anteriormente. 0 adjetivo "bom" aplicado aos pratos é, ao mesmo tempo, subjetivo e construído coletivamente e, segundo nos deu a parecer, refere-se simultaneamente à qualidade dos ingredientes utilizados e às habilidades do 
cozinheiro. Quando usam o adjetivo "magra” não querem dizer mais pobre ou menos rica, mas menos gordurosa. Essa seria a diferença entre as feijoadas de acordo com as classes que a fazem e a comem.

A feijoada caseira é mais valorizada em termos de sabor e requinte, contudo, a praticidade é outro valor que nossas entrevistadas têm em alta conta. "Já limpei tanto a casa dos outros, trabalho a semana inteira e quer que eu me mate na cozinha no fim de semana? Não mesmo”, diz Gláucia que já foi empregada doméstica, valoriza seu trabalho e, sobretudo seu tempo de lazer. Para aproveitar esse tempo de lazer dos fins de semana, Gláucia e outras entrevistadas disseram comprar feijoada pronta em latas ou em embalagens tipo longa vida a fim de servi-las com ostentação e pouco trabalho. Aos conteúdos das embalagens de feijoada são acrescidas linguiças e temperos, de modo a singularizar o prato massificado e, ao mesmo tempo, "enriquecê -lo”, o que é essencial para ser considerado uma comida de bom gosto e continuar sendo considerado uma refeição:

0 signo da velocidade anula e desmoraliza as demoradas preparações que orgulhavam os antigos gourmets. A industrialização dos alimentos reduz a cozinha a um armário de latas. A técnica essencial limita-se, a saber, abrir uma lata sem ferir os dedinhos. Um jantar egresso de latas é ato de comer mas não no nível de uma refeição. (CASCUDO, 2004, p.36)

Vimos então que o arroz e o feijão são afastados, mas não excluídos da dieta. 0 feijão torna-se feijoada ou tutu paulista, o arroz ganha a forma de risotos, ainda que apareça nas entrevistas que "nada é mais gostoso que arroz, feijão e ovo frito", desde comidos raramente para não estragar a dieta e em situações privadas. É inadmissível comer esse prato em um restaurante por quilo, mas admite-se comer arroz e feijão quando revestido de requinte.

0 binômio arroz-feijão, por ser considerado prato forte, destinado à população que “trabalha no pesado", tende a ser excluído das dietas dos sujeitos da classe social aqui apresentada, que não querem nem executam trabalhos que exigem força física. Existe, portanto, uma divisão social, entre o consumo de comidas de "sustança" e o de alimentos mais leves ligados ao tipo de trabalho que demarca uma fronteira social.

\section{0 império ligth-diet e a "sociedade lipo- fóbica"}

Nossas entrevistadas mostraram a tendência para afastar o arroz e feijão de seus pratos, ainda que não de suas mesas, e justificaram essa opção por receio de engordar, para emagrecer ou manter o peso. Por essas mesmas razões, as mulheres com quem conversamos afirmaram que passaram a ter preferência por rótulos light e diet na escolha de alimentos. Se houver na prateleira dois produtos similares, a preferência será o rotulado de light ou diet e, em caso não haja essa opção, também se consultam os indicadores nutricionais presentes nas embalagens. A escolha será guiada pela menor taxa calórica seguida pela menor taxa de açúcares, carboidratos e sódio.

As mulheres em ascensão são orientadas em suas escolhas pelas propagandas do império diet e light em revistas, televisão, internet, academias, etc., pelo discurso biomédico e pela observação de pessoas da mesma classe. A frequência em restaurante e em lojas especializadas, além de promover saciedade, cumpre também função educativa em relação aos modos de ser que 
compõem determinadas fachadas sociais (GOFFMAN, 1999) correspondentes a papéis de classe:

Venho aqui nessa loja de produtos naturais, light e diet porque todas as minhas amigas vêm, é bom comprar aqui, e tem muita novidade, coisas que não engordam, mas são gostosas. Também gosto de ver receitas novas e pedir para moça que trabalha lá em casa fazer. A gente gosta de experimentar, olha esse tomate seco que delícia, isso na salada de rúcula e queijo light, e eu nem conhecia, li numa receita aqui. Então eu venho pelo menos uma vez por semana, aqui tem verdura também, já aproveito. (Suzana, 32 anos, sempre foi pobre e morou na periferia, mãe de dois filhos, fez universidade e se casou, ascendendo socialmente)

Esses discursos demonstram a vinculação de tipos de corpo correspondentes às classes em vários aspectos, inclusive os que passam pelo peso, formato e cor de cabelos, pele, unhas, além das vestimentas. 0 consumo diet e light é justificado pela procura de saúde das próprias mulheres e de seus filhos, apesar de ressaltarem que os produtos de baixa caloria acabam sendo consumidos por elas mesmas, não tendo um gosto partilhado na família. Em geral, compra-se dois tipos de refrigerantes: o diet para o consumo da mulher, e o calórico que é o mais apreciado pelas crianças e parte dos maridos.

Também encontramos a incorporação do discurso biomédico que lhes chega por vários mediadores culturais, como programas de TV, jornais e revistas que difundem um tipo específico de relação com o próprio corpo. Há que lembrarmos a valorização da saúde como capital, apontada por Lipovestky (2008) como uma das características da sociedade contemporânea.
As escolhas por pratos menos gordurosos e mais saudáveis, considerados quase como sinônimos nos discursos, manifestam-se também na introdução das verduras e saladas nas dietas. As saladas devem estar na mesa para que todos da família consumam e se beneficiem destes alimentos que estão agora sendo considerados saudáveis, ainda que a maior consumidora desses pratos seja a mulher.

Conversando sobre os hábitos anteriores, vemos que a salada quase não era consumida. Sílvia conta que sua mãe "sempre dizia que comer salada não mata a fome de quem dá duro no trabalho", além do que ela "só conhecia salada de tomate com cebola e de repolho”. Hoje, a situação mudou:

A semana toda evito comer muita coisa que engorda assim me peso na sexta feira e então, posso abusar mais no fim de semana, mas se tiver light ou diet, prefiro esses, porque assim fica mais fácil manter a linha e não destruir tudo que consegui na semana, com uma alimentação mais leve e academia. (Neide, 38 anos, mora com o namorado, mas se considera solteira, abriu um comércio e ascendeu socialmente)

0 que se percebe é que os hábitos de consumo de alimentos também estão interligados a uma moda aceita pelo grupo em questão, já que os membros de uma mesma camada social comentam entre si sobre o que comem e consomem, delimitando, assim, os produtos que marcam seu lugar social. "As pessoas usualmente compram o que veem que os amigos usam e desfrutam. Os contatos sociais não são aleatórios" (DOUGLAS; ISHERWOOD, 2009, p. 152).

Para essas consumidoras, é importante poder escolher os alimentos menos calóricos e criar critérios de vantagem e 
desvantagem que justifiquem reflexivamente suas opções. "Come-se a mesma coisa, porém engordando menos”, dissenos uma das entrevistadas ao deixar claro que essa preocupação era sua, especificamente, enquanto mulher, já que são as mulheres que mais sofrem com gorduras localizadas e celulites, e é sobre as mulheres que mais recai o ideal de beleza associado à magreza.

Toda essa discussão remete-nos à ideia de Claude Fischler, exposta em entrevista a Mirian Goldenberg, sobre a "sociedade lipofóbica":

As sociedades contemporâneas ocidentais são lipofóbicas, têm horror à gordura e aos gordos. Elas também criaram o conceito de obesidade. 0 que é considerado obeso, hoje, é alguém que poderia ser visto como normal, gordinho, gordo, mas "gordo como se deveria ser". 0 que era considerado um indivíduo normal, hoje pode ser visto como gordo, ou até muito gordo. Basta olhar as fotos de Marylin Monroe e comparar com as das atrizes americanas de hoje. Ela não seria considerada gordinha ou até mesmo gorda por algumas? Não só as atrizes, mas se observamos as modelos ao longo dos anos, é fácil verificar que elas estão cada vez mais altas e cada vez mais magras. E são essas mulheres que trazem novos modelos de corpos que se tornam padrões a serem imitados por outras nas sociedades ocidentais contemporâneas. Cada vez mais jovens, mais altas e, especialmente, cada vez mais magras. (FISCHLER, em entrevista a GOLDENBERG, 2011, p.242)

Todas as entrevistadas estavam preocupadas em estarem gordas ou engordarem, inclusive mostravam preocupação com a massa corporal de seus filhos e maridos. Para Paula:
Gosto de comer saudável, com saúde, que não engorde, não tenha gordura. Quando mudamos para cá e o dinheiro começou a entrar, começamos a comer muita besteira, comer coisa gostosa e não estávamos preocupados com a saúde, aí fui fazendo amizade com as mulheres daqui e todas iam na academia, seus filhos fazem natação, balé, tênis, os maridos caminhavam, também iam a academia, elas se preocupavam em estar magras e bonitas para a sociedade, isso faz bem sabe, autoestima. Estar bonita e com saúde, toda a família, isso é muito importante. Aí conversamos lá em casa e decidimos mudar nossos hábitos, começamos a fazer esporte e comer coisas mais saudáveis, isso foi muito bom. (Paula, 46 anos, três filhos e um enteado, casou muito cedo, estudou psicologia, fez mestrado em psicologia clínica, ascendendo socialmente, hoje tem uma empresa de atendimento psicológico e terapias alternativas, sócia com mais três amigas)

Paula, preocupada com a saúde da família e sua felicidade, passou a se preocupar muito mais com aprender novas dietas, com o que é saudável e menos gorduroso ou que não engorde.

Nas últimas décadas, houve um aumento da preocupação com a aparência, com a imagem corporal e com o seu controle. É nesse momento que se agrava o excesso de preocupação com o corpo e, consequentemente, com o peso e, também, com a dieta para manter o peso desejado. Corpo, peso e dieta se combinam para criarem uma nova obrigação social e, diria mais ainda, moral. Os médicos e nutricionistas passaram a ter um poder até então desconhecido. 0 discurso sobre os males de uma má alimentação passou a ser amplamente difundido por meio dos médicos, nutricionistas e outros profissionais. 
Além do perigo de engordar, outros males foram associados a uma alimentação inadequada: diabetes, doenças cardiovasculares, câncer, etc. (FISCHLER, em entrevista a GOLDEMBERG, 2011, p. 243-243)

Com o consumo de produtos diet e light, vende-se a promessa de inserir cada consumidor no padrão de beleza, magreza e saúde, lembrando que, na sociedade hipermoderna, nos termos de Lipovestky (2008), a saúde é vista como responsabilidade individual.

A representação de corpo é diferente entre as classes sociais: enquanto as classes média e alta valorizavam um corpo magro como representação de ascensão, as camadas populares associavam a magreza à fraqueza ou à incapacidade para o trabalho. No entanto, também as gerações mais jovens, de todos os estamentos sociais, passaram a valorizar a magreza. A preferência de dietas light por mulheres de todas as camadas sociais pode ser verificada por duas razões, seja pelo ideal de beleza associado à magreza, seja relacionada à preocupação e cuidado de si, comportamentos também considerados femininos.

0 "comer de tudo" é valorizado quando as opções não são tantas, mas esse "comer de tudo" dá lugar a restrições alimentares que conduziriam à obtenção de beleza, magreza e saúde. Uma das entrevistadas contou que nunca havia visto maionese light no supermercado ${ }^{3}$ que frequentava, porém nos supermercados que agora frequenta, mais dirigidos às camadas médias e altas, há setores inteiros de produtos assim. Esse gosto novo, o gosto light, apesar de restritivo, não exclui o prazer da alimentação, mas com ele se coaduna. Assim, aos poucos, o gosto antigo vai sendo abandonado, como o ovo frito em muito óleo, as peles de frango e as coxinhas de bar.

\section{A pressa e os brinquedinhos de cozinha}

As mudanças relacionadas à percepção e ao uso do tempo no mundo contemporâneo permitem, conforme Pais (2010), que se diagnostique um apressuramento da vida urbana, o que também aparece na redução do tempo que se quer disponibilizar para o preparo e o consumo de alimentos. Essas mudanças acabam causando impacto nos hábitos alimentares da classe média em ascensão e têm gerado reações, como o movimento Slow Food.

Todas as nossas entrevistadas trabalham fora de casa, a maioria é responsável por levar e buscar os filhos na escola, fazer as compras da casa e organizar os afazeres de empregados domésticos. Enfım, todas falam de pressa, de correria, de fazer muitas coisas ao mesmo tempo, e é, nesse contexto, que existe uma busca por utensílios que facilitem (e em certo sentido "glamourizem") o preparo dos alimentos.

Encontramos em muitas falas a valorização de equipamentos tais como processadores de alimentos, panelas elétricas que fritam sem óleo e que cozinham arroz, máquinas que preparam a massa do pão, cafeteiras expressas, grills, fornos, abridores de latas elétricos, panelas de fondue, etc. Enfım, o consumo de utensílios chamados por vezes de "brinquedi-

3. A entrevistada citou um supermercado específico que vende por atacado a preços populares em Cuiabá. Fomos conferir e, de fato, no supermercado em questão, não há maionese light de nenhuma marca, o que nos fez refletir acerca da própria distribuição dos alimentos direcionados à camadas populares agindo sobre a constituição de determinados modelos de corpos. 
nhos" permite que tanto ela como qualquer um da família possa preparar os alimentos sem perder tempo e sem muito trabalho. Porém, muitas vezes, esses equipamentos só garantem uma satisfação técnica, porque, segundo algumas entrevistadas, usá-los pode ser difícil e ainda "fazer a maior sujeira”.

Existe uma valorização da rapidez no preparo ao mesmo tempo em que se valoriza a técnica, o requinte. 0 preparo demorado é sintoma de sofısticação e de expertise, como se o tempo agregasse um sabor extra no que é servido. Mas, sendo o tempo um recurso escasso em larga medida, para não fazer sujeira e comer bem, a ida aos bons restaurantes funciona como saída estratégica. $\mathrm{Na}$ impossibilidade de bons restaurantes, também funcionam as rotisserias e estabelecimentos que servem comida pronta ou semipronta, além das comidas globalizadas de franquias de fastfood, como Mac Donalds (comida americana), Habibs (comida árabe), China in Box (comida chinesa), Pizza Hut e Dilleto (comida italiana).

Cascudo (2004, p. 37) discorre sobre a cozinha considerada internacional, aquela subjugada pela propaganda e convencionada de forma tal que constitui um cardápio que "ninguém gosta e com que todos se habituam”. Apesar da padronização dos pratos adquiridos, a finalização do prato, realizada no forno, panela ou processador acaba por singularizar, adaptando o gosto padronizado às configurações particulares.

(...) os apetites são substituídos pelas fomes e a inquietação moderna impossibilita as lentas paciências operadoras, realizando as maravilhas do paladar. 0 comum, natural, obrigatório e lógico para a mulher em nossos dias é saber improvisar um jantar, enfeitar o prato, disfarçar a fisionomia de cada espécie deglutível com a ciência nefasta dos colorantes mascaradores, das mistificações sugestivas, da incaracterização gustativa. (CASCUDO, 2004, p.36)

Nos novos hábitos desta camada em ascensão, a praticidade, rapidez e sabor são os adjetivos mais presentes nas falas durante as descrições das novas escolhas que se levam a cozinha e à mesa de refeições.

Uma vez, eu comprei um monte de yakisoba do China (refere-se ao China in Box) e esquentei na minha Wok, pus numa travessa bem bonita e fingi que eu que fiz (risos). Enganei todas as minhas visitas. (Marta, 39 anos, microempresária. Ascendeu socialmente através do trabalho. Hoje ajuda toda sua família)

Os "brinquedinhos" culinários estão na cozinha para facilitar o dia a dia, mas também são usados para demonstrar o poder de consumo da proprietária. Assim, o macarrão chinês servido pela Marta só convenceu sua plateia que acreditou em sua encenação cínica (GOFFMAN, 1999) por causa dos objetos que contribuíram para sua fachada: panela Wok, hashis e boas travessas decorativas. Os desejos de compra são criados pelas indicações de outras pessoas da mesma camada.

Eu fiquei louca para comprar a panela que frita sem óleo, todas as minhas amigas já tinham, menos eu. Um dia, conversando com elas na casa da "fulana", decidi comprar no shopping perto de casa, comprei antes de voltar para casa, e usei no mesmo dia. Comprei no cartão em dez vezes, como sempre faço, mas comprei. (Stela, 32 anos, dois filhos, ascendeu socialmente fazendo universidade) 
Nas viagens de lazer, mulheres também buscam comprar equipamentos para compor a cozinha da família, já que, em muitos casos, certos produtos não se encontram à venda no Brasil ou são muito caros. Além de exibir o próprio objeto, falar de sua nacionalidade torna sua posse ainda mais especial: "chique anunciar que tal utensílio foi trazido de Miami ou de Milão, etc.”

Nas entrevistas, as mulheres apontam esse hábito nas viagens e dizem gostar dessas compras, principalmente porque existe uma ligação desse consumo a um status de poder e de estar "antenada" ao mais novo brinquedo da moda. A celebridade Ana Maria Braga, conhecida inclusive por dar receitas na televisão, tem o mesmo discurso e, certamente, influencia suas expectadoras enquanto formadora de opinião:

Sou apaixonada por equipamentos culinários. Nas minhas viagens, as lojas de utilidades domésticas são passagens obrigatórias e tudo o que eu costumo trazer para uso pessoal tento levar para o 'Mais Você', que não deixa de ser uma extensão da minha casa, revela. (SERENZUELLA, 2014)

O comportamento de compra assumido reflexivamente por nossas entrevistadas contribuiu para confirmar nossa hipótese de que as práticas e rituais de consumo agem positivamente no sentimento de pertencimento. Não menos importante, é a consciência destas consumidoras em escolher produtos $\mathrm{x}$ e não $\mathrm{y}$, já que se quer atingir um objetivo que, nesse caso, é fincar sua âncora nessa nova classe social e, principalmente, nunca mais voltar à camada anterior:

Depois que compramos esse apartamento muito maior e bonito, só entra na minha cozinha coisa de qualidade; gosto de trazer coisas de nossas viagens, adoro eletrodomésticos que facilitem minha vida Quando fui para Miami, me acabei de comprar, lá tem de tudo e muito mais bonito e barato, não quero ter uma cozinha como tínhamos lá em casa antes de mudar, era tudo velho, feio, atrasado. Agora não, procuro estar antenada nas novidades pelos programas de TVs que sempre estão anunciando coisas novas e também converso bastante sobre isso com minhas amigas do condomínio, elas sempre me dão um toque. (Lilian, 40 anos, um filho e dois enteados, ascendeu socialmente com o casamento)

Dessa maneira, as protagonistas dessa pesquisa fazem questão de conhecer, ter e mostrar para as "amigas" que possuem "brinquedinhos" da moda culinária, como no caso da panela que frita sem óleo de Stela, cuja importância transcendia as capacidades do produto (fritar sem óleo) e os benefícios de seu uso (manter a saúde ingerindo menos gordura saturada). A panela da Stela era importante para que ela não fosse a única que ainda não tinha esse bem.

\section{Comida mundializada e restaurantes chi- ques}

Os discursos analisados manifestam a preferência das entrevistadas por restaurantes com comida internacional, como casas italianas, tailandesas, árabes e francesas. Também têm presença nos discursos, os bistrôs, os restaurantes regionais e, principalmente, os que se definem como alta gastronomia contemporânea. Contudo, esses restaurantes são ocasiões especiais e seus preços não permitem uma ida constante. Notamos que o mais valorizado, na ida a esses estabelecimentos, é a 
experiência de comer uma comida assinada por um chef. Os restaurantes mais efetivamente frequentados são restaurantes a quilo escolhidos de acordo com a variedade e qualidade das opções em tese, mas também são escolhidos pela localização (bairros nobres e shoppings centers), preço (evitam os muito baratos, pois não são confiáveis) e pelos frequentadores (seguem indicações). As escolhas são baseadas sempre na confirmação do pertencimento à classe ali representada.

A maioria das mulheres diz que aprendeu a cozinhar com a própria mãe, mas, ao ascender socialmente, ampliam-se os novos aprendizados, vindos de novos ensinamentos e, nesse contexto, a ida aos restaurantes adquire função pedagógica, assim como assistir televisão:

Adoro patê com azeite extra virgem. Eu nem sabia que existia isso antigamente. $\mathrm{Pa}-$ tê? Quem come patê? Minha mãe nunca fez, nunca fez nada com molho branco, nem quatro queijos. Isso não existe na mesa do pobre. Nós viajamos todas as férias e vamos só em restaurantes bons, comemos mesmo à vontade. Aqueles petiscos todos na praia, camarão, tudo uma delícia. (Margarida, 46 anos, mulher de um ex-pedreiro, hoje sócio de uma empresa de taxis, dois filhos, três netos, considera que ascendeu socialmente pela mudança de renda do marido)

Nas horas de lazer se quer comer com tranquilidade, porém a maioria das entrevistadas, salvo duas exceções de pessoas que dizem apreciar a atividade culinária e fazem dela um hobbie, relaciona o cozinhar com perder tempo de descanso, e então prefere ir a restaurantes ou comprar comidas prontas ou semiprontas.
Nos fins de semana gostamos de sair por ai para comer coisas diferentes, conhecer novas comidas, ou então compramos algo que se faz rapidinho, como comidas congeladas e apenas coloco no micro-ondas e se for o caso, dou uma gratinada no forno. (Flávia, 26 anos, professora de educação física, mãe de dois filhos, casada com contador, abriu uma academia com mais dois sócios e ascendeu socialmente)

Em nossas folgas gostamos de sair em família para comer fora, conhecer restaurantes, ver pessoas, a família toda gosta, eu gosto muito porque me ajuda a ter ideias para fazer lá em casa as comidas que conheço nos restaurantes. (...) Outro dia comemos vitela ao molho roti, uma delícia, olhei a receita na internet e minha secretária faz agora lá em casa, todo mundo adora. (Beth, 44 anos, mãe solteira de três filhos, dois netos, com a ajuda dos filhos ascendeu socialmente, e casou-se novamente)

Prefiro comer fora quando minha empregada está de folga aos domingos e feriados, assim não fazemos bagunça, não tem louça, gosto de sair junto com meu marido e filhos, ver gente, aproveitar e descansar com eles; há uns anos atrás a gente nunca fazia isso. (Maria, 46 anos, mãe de três filhos, ascendeu socialmente com o casamento)

Por diversos motivos, essas mulheres gostam de unir lazer e comer fora. Trata-se de um hábito novo adquirido, no qual elas repetem sempre que podem como um prêmio merecido pela nova conquista social. Além de fazer parte agora também de um mediador cultural, já que as informações obtidas naquele espaço acabam sendo levadas para dentro de suas casas com a família com um sentimento de pertencimento. 
Meu marido e eu adoramos receber amigos em casa, e é fundamental ter a mesa bem arrumada, acho lindo, então além da comida, é claro, fico olhando como eles decoram as mesas, se usam toalhas, os guardanapos, as taças, os talheres, aí depois eu compro igual, ensino minha empregada, fica lindo e o melhor, todo mundo elogia. Por exemplo, aprendi neste restaurante que chique é guardanapo de pano, e que tem uns prendedores para colocar em cima do prato, agora lá em casa quando vai gente é sempre assim, tenho de várias cores e tipos, e os copos... os copos, tem cada um mais lindo do que outro, adoro os coloridos; antes, era copo de requeijão mesmo, guardanapo de papel, ficava muito feio, as pessoas reparam. Mandei gravar meu nome e de meu marido nos pratos, vi isso na Argentina em um restaurante que fomos lá, tinha o nome do chefe de cozinha gravado nos pratos, achei muito legal e fiz em casa. (Luciana, 36 anos, três filhos, morava na zona rural, fez universidade, é secretária e casou com fazendeiro ascendendo socialmente)

Essas famílias em ascensão gostam e aprendem em restaurantes, sobretudo os de comida internacional mais acessíveis, que há pouco tempo passaram a fazer parte da cidade no processo de modernização a que a mesma se vê submetida. Salientamos que nossas entrevistadas não frequentam tão somente restaurantes de cozinha internacional, seja ele de alto padrão ou mediano, mas frequentam também redes de franquia, nacionais e estrangeiras, que vendem comida rápida e globalizada.

Com tudo o que caracteriza a contemporaneidade e a vida urbana, as transformações nos hábitos alimentares podem ser vistas na frequência aos restaurantes, no apressuramento e também nas disponibilidades de consumo.
Produto deste modus vivendi urbano, a comensalidade contemporânea se caracteriza pela escassez de tempo para o preparo e consumo de alimentos; pela presença de produtos gerados com novas técnicas de conservação e de preparo, que agregam tempo e trabalho; pelo vasto leque de itens alimentares; pelos deslocamentos das refeições de casa para estabelecimentos que comercializam alimentos - restaurantes, lanchonetes, vendedores ambulantes, padarias, entre outros; pela crescente oferta de preparações e utensílios transportáveis; pela oferta de produtos provenientes de várias partes do mundo; pelo arsenal publicitário associado aos alimentos; pela flexibilização de horários para comer agregada à diversidade de alimentos; pela crescente individualização dos rituais alimentares. (GARCIA, 2003, p. 484)

Segundo a autora, há o risco, com a globalização, de uma alimentação desenraizada em que tudo pode ser encontrado em qualquer lugar do mundo e readaptado de algum modo. As comidas típicas foram desenraizadas e permanecem modificadas para adaptar-se ao mundo. Por exemplo, os padrões de fastfood americanos foram disseminados em todas as regiões do globo e, certamente, se fazem ver no Centro-Oeste brasileiro como uma das opções alimentares associadas ao estilo de vida moderno, presentes, de modos diferentes, em diferentes camadas sociais.

A globalização atinge a indústria de alimentos, o setor agropecuário, a distribuição de alimentos em redes de mercados de grande superfície e em cadeias de lanchonetes e restaurantes. A difusão da ciência nos meios de comunicação e o uso do discurso científico na publicidade de alimentos também exercem seu papel no cenário das mudanças alimentares. Embora nos países mais pobres es- 
tas tendências de consumo estejam distribuídas diferentemente nos segmentos de classes sociais de acordo com as possibilidades de acesso aos bens de consumo, no plano simbólico os desejos de consumo por si só marcam uma inclinação a este perfil alimentar. A estandardização de certas instâncias das práticas e do comportamento alimentar facilitam as mudanças na alimentação que vão sendo incorporadas como parte do modo de vida, como consequência deste. Pressionadas pelo poder aquisitivo, pela publicidade e praticidade, as práticas alimentares vão se tornando permeáveis a mudanças, representadas pela incorporação de novos alimentos, formas de preparo, preparo, compra e consumo. Contudo, é possivel que tais mudanças encontrem mais ou menos resistência, dependendo da cultura alimentar e da consolidação de suas práticas estabelecidas e simbolicamente valorizadas. (GARCIA, 2003, p. 485)

Sendo assim, a alimentação globalizada traz a ideia de uma universalidade de produtos alimentares, não só do ponto de vista econômico, mas também cultural e social. Nessa alimentação, o consumidor adquire padrões, estilos, modas e escolhas que acabam sendo difundidos em bens globais. Contudo, também se percebe na inserção dessas novas escolhas, a preservação de hábitos alimentares regionais em manter certos alimentos. Segundo essa visão, a ideia de um regime alimentar global ajuda a explicar a unificação de escolhas e práticas em torno do mundo, bem como a crescente variação nos bens e escolhas ligados à cultura alimentar.

Considerando as falas das nossas entrevistadas e as singularidades que caracterizam a capital Cuiabá, vemos que, apesar da presença marcante das visitas às redes de fastfood, a culinária regional é valorizada. Para Gushiken et al (2013, p. 59):
A culinária tradicional na cidade contemporânea se apresenta em meio a um processo de hibridação cultural próprio das condições históricas que formataram as sociedades latino-americanas, incluindo a brasileira, no desenvolvimento do capitalismo histórico. Toda a produção da culinária tradicional local divide espaço nos dias de hoje com a chamada comida mundializada, produzida tanto em sofisticados restaurantes, lojas de redes de franquia e modestos equipamentos montados nos populares lanches de rua: cachorro-quente, hambúrguer, cheese-burger, pizza, pastel, sushi, canelloni, espaguete, muffin, cookie, taco, churro, baguete, quibe, esfiha, pão de queijo, chipa, estrogonofe, batata frita, batata assada com recheio.

Os autores, apesar de reconhecerem a globalização, percebem que esse processo não resulta apenas em massificação de gostos, mas também demanda a produção da diferença (GUSHIKEN, SILVA, MAGALHÃES 2013). Cuiabá tem rica gastronomia, influenciada por seus muitos fluxos migratórios. Os peixes de água doce, as frutas, os temperos se veem acompanhados de produtos internacionais ou locais.

À fartura que se insinua na oferta de comida regional se suplementa ainda uma variedade mercadologicamente crescente de restaurantes de comida internacional (árabe, italiana, japonesa, americana, mexicana, chinesa, francesa) e brasileira (nordestina, mineira, goiana, gaúcha, paraense), com oferta igualmente crescente de bebidas que se incorporam ao cotidiano local através de supermercados, a maioria de redes locais, alguns dos quais funcionando 24 horas: cartas de vinhos (chilenos, argentinos, portugueses, italianos, franceses, australianos, sul-africanos, brasileiros), cervejas (alemãs, irlande- 
sas, uruguaias, escocesas, bolivianas, belgas), destilados (poloneses, russos, ingleses, americanos, escoceses). (GUSHIKEN, SILVA, MAGALHÃES, 2013, p. 61)

O licor de pequi pode acompanhar um prato típico da gastronomia internacional, e um vinho estrangeiro pode ser degustado com pratos considerados tipicamente regionais.

A modernização permite uma troca de informações, muitas vezes expressas em padrões de consumo. À mesa da moradora de Cuiabá em ascensão estão o vinho, o sushi, o estrogonofe, o churrasco, a feijoa$\mathrm{da}$, a tapioca, a ventrecha de pacu, a maria izabel, a galinhada. De sobremesa, podem servir petitgateau, tiramissu e furrundú.

É preciso salientar que nas feiras locais se vendem tanto comidas regionais quanto inspiradas pela culinária internacional e os restaurantes regionais situam-se na faixa de preço dos internacionais, servindo ao turismo que se beneficia da singularidade gastronômica. Essas mulheres só frequentaram algum restaurante regional ou internacional após a ascensão.

Gostamos muito de ir ao restaurante do espanhol, porque ele valoriza nossa cultura, adoro a paella de pacu e a de pequi que ele faz, também gosto muito do doce que ele mistura o furrundú nosso com os cremes pasteleiros da Espanha. Sempre que podemos vamos para experimentar as novidades cuiabanas espanholas que ele prepara, é um luxo. (Rita, 42 anos, mãe de dois filhos, ascendeu socialmente no casamento com fazendeiro, estudou educação física e hoje é proprietária de uma academia de ginástica)

Segundo Santos (2005), as cozinhas - tanto locais, regionais, nacionais como internacionais -, são resultados da miscigenação cultural, mostrando assim que as culinárias desvendam trocas culturais existentes no país, na região, no mundo, através da alimentação.

Hoje os estudos sobre a comida e a alimentação invadem as ciências humanas, a partir da premissa que a formação do gosto alimentar não se dá, exclusivamente, pelo seu aspecto nutricional, biológico. 0 alimento constitui uma categoria histórica, pois os padrões de permanência e mudanças dos hábitos e práticas alimentares têm referências na própria dinâmica social. Os alimentos não são somente alimentos. Alimentar-se é um ato nutricional, comer é um ato social, pois constitui atitudes, ligadas aos usos, costumes, protocolos, condutas e situações. Nenhum alimento que entra em nossas bocas é neutro. A historicidade da sensibilidade gastronômica explica e é explicada pelas manifestações culturais e sociais, como espelho de uma época e que marcaram uma época. Nesse sentido, o que se come é tão importante quanto quando se come, onde se come, como se come e com quem se come. Enfım, este é lugar da alimentação na História. (SANTOS, 2005, p. 176)

Dessa maneira, ao encontro de nossa pesquisa, o que se percebeu foi que existe uma hibridação cultural na culinária de Cuiabá, na qual suas cozinhas aceitam inovações e toques internacionais, e os restaurantes estrangeiros também se adaptam ao consumo da população local. Compreendemos que mesmo inserindo pratos internacionais em suas dietas, as nossas entrevistadas não deixam de apreciar os pratos regionais e, mesmo consumindo pratos globalizados de redes de fastfood, buscam por uma singularidade ao acrescentar ingredientes que dão uma espécie de assinatura a esses pratos, o 
que relativiza a ideia de pasteurização dos gostos na cultura contemporânea.

\section{Considerações finais}

Ao longo de nossa reflexão, analisamos alguns discursos sobre o consumo relacionado aos hábitos alimentares de mulheres da camada média urbana em ascensão social. A mobilidade social acabou favorecendo a introdução de novos hábitos, a utilização de novas tecnologias, alterando o saber-fazer e impondo novos sentidos às práticas alimentares e aos próprios alimentos, todavia os hábitos construídos anteriormente não foram totalmente abandonados.

Acreditamos que essa parcela da sociedade entrevistada, procura

hoje nos bens e serviços suas propriedades simbólicas, como vias expressas de obtenção e manutenção de um status (BARBOSA, 2006, p.11).

Apesar de nossas entrevistadas demonstrarem desejo de estada e permanência na condição social superior, não vimos ocultação de sua origem social, tampouco vergonha, percebemos uma valorização da passagem de uma camada a outra, vivenciada como uma conquista, trazendo sentimentos de gratificação ao esforço desprendido para obtenção de pertencimento a uma classe mais abastada do que a anteriormente vivida por elas.

Considerando os próprios hábitos destacados pelas entrevistadas, percebemos uma alteração do saber fazer, sobretudo pelos novos conhecimentos demandados pelas diferentes tecnologias que adentram a cozinha com toda a sorte de utensílios, mas também pelas diferentes técnicas aprendidas através de programas de televisão, in- ternet e idas a restaurantes, além de conversas com amigos e conhecidos. Notamos também uma preocupação em manter o corpo magro e saudável, e como a conquista ou manutenção desse corpo socialmente valorizado resulta da imposição de uma série de disciplinas que incluem exercício físico, abstenção de arroz e feijão e predileção por pratos pouco calóricos e produtos das categorias light e diet. Em relação à escassez do tempo, a praticidade se faz presente na busca por refeições prontas e semiprontas que ganham uma singularização ao serem ressignificadas através do acréscimo de ingredientes ou por meio de alguma técnica culinária. Através da transformação dos hábitos alimentares foi possível observar a atuação do consumo no sentimento de pertencimento e adequação dessas mulheres ao novo lugar social que passaram a ocupar.

\section{Referências}

AMON, D.; MENASCHE, R. Comida como narrativa da memória social. Sociedade e Cultura: Revista de Pesquisas e Debates em Ciências Sociais-UFG, v. 11, n.1, p.13-21, 2008.

ASSUNÇÃo, V. Comida de mãe: notas sobre alimentação, família e gênero. Caderno Espaço Feminino, Uberlândia, v.19, n.1, jan.-jul./2008.

BARBOSA, L.; CAMPBELL, C. Cultura, consumo e identidade. Rio de Janeiro: FGV, 2006.

BARBOSA, L. Feijão com arroz e arroz com feijão: o Brasil no prato dos brasileiros. Horizontes Antropológicos, Porto Alegre, ano 13, n. 28, jul./dez, p. 87-116, 2007.

BOURDIEU, P. A economia das trocas simbólicas. São Paulo: Perspectiva, 1987.

BRAGA, V. Cultura alimentar: contribuições da Antropologia da alimentação. Saúde em revista, Piracicaba, v. 6, n. 13, p. 37-44, 2004. 
CAMPBELL, C. Eu compro, logo sei que existo: as bases metafísicas do consumo moderno. In: BARBOSA, L.; CAMPBELL, C. (Orgs.) Cultura, consumo e identidade. Rio de Janeiro: FGV, 2006, p. 47-64.

CANCLINI, N. G. Consumidores e cidadãos: conflitos multiculturais da globalização. Rio de Janeiro: UFRJ, 2010.

CASCUDO, L. C. História da alimentação no Brasil. São Paulo: Global, 2004.

DOUGLAS, M., ISHERWOOD, B. 0 mundo dos bens: para uma antropologia do consumo. Rio de Janeiro: UFRJ, 2009.

ELIAS, N. 0 processo civilizador: uma história dos costumes. Rio de Janeiro: Jorge Zahar, 1994.

FISCHLER, C. Gastro-nomia y gastro-anomia: sabidura del cuerpo y crisis biocultural de la alimentación contemporánea. In: CONTRERAS, J. Alimentación y Cultura: necesidades, gustos y costumbres. Barcelona: Universidad de Barcelona, 1995, p. 357-380.

GOLDEMBERG, M. Cultura e gastro-anomia: psicopatologia da alimentação cotidiana. Entrevista com Claude Fischler. Horizontes Antropológicos, Porto Alegre, v. 17. n. 36, jul.dez./ 2011, p. 235-256. Disponivel em: <http:// www.scielo.br/scielo.php?script=sci_arttextEtpi$\mathrm{d}=$ S0104-71832011000200010 $>$. Acesso em: 3 abr. 2016

GARCIA, R. Reflexos da globalização na cultura alimentar: considerações sobre as mudanças na alimentação urbana. Revista de Nutrição, Campinas, out./dez., p. 483-492, 2003.

GOFFMAN, E. A representação do eu na vida cotidiana. Petrópolis: Vozes, 1999.

GUSHIKEN, Y. et al. Rumores e sabores de uma feira: culinária popular e cosmopolitismo banal em Cuiabá. Campinas, Revista do Laboratório de Estudos Urbanos do Núcleo de Desenvolvimento da Criatividade - RUA, n. 19, v.1, p. 56-72, 2013. Disponivel em: <http://www.labeurb.unicamp.br/ rua/pages/home/capaArtigo.rua?id=144>. Acesso em: 6 mar. 2016.
JIMENEZ-JIMENEZ, M. L. Domésticas: cotidianos na comensalidade. 2016. 150f. Dissertação (Mestrado em Estudos de Cultura Contemporânea) Faculdade de Comunicação e Artes, Universidade Federal de Mato Grosso, Cuiabá, 2016.

LIPOVETSKY, G. A felicidade paradoxal: ensaio sobre a sociedade de hiperconsumo. São Paulo: Companhia das Letras, 2008.

MAGALHÃES, C. Comida de comer comida de pensar. Revista Cadernos de Debate, Núcleo de Estudos e Pesquisas em Alimentação, Campinas, v. III, p. 29-57, 1995.

MINTZ, S. Comida e antropologia: uma breve revisão. Revista Brasileira de Ciências Sociais. v. 16, n. 47, p. 32-47, 2001.

NERI, M. C. A nova classe média. Rio de Janeiro: FGV/ IBRE, CPS, 2008. Disponivel em: <http:// www.cps.fgv.br/ibrecps/M3/M3_TextoFinal.pdf>. Acesso em: 20 fev. 2011.

OLIVEIRA-CRUZ, M. F. Estrutura de sentimento como hipótese cultural: uma perspectiva para pensar a "nova classe média". In: CONGRESSO INTERNACIONAL COMUNICAÇÃO E CONSUMOCOMUNICOM, 3, 2013, São Paulo, Memória, comunicação e consumo: vestígios e prospecções, III CONGRESSO INTERNACIONAL DE COMUNICAÇÃO E CONSUMO. São Paulo: ESPM, 2013. Disponível em: <http://www.espm.br/download/ Anais_Comunicon_2013/comunicon_2013/gts/gtcinco/GT05_OLIVEIRACRUZ.pdf>. Acesso em: 21 dez. 2014.

PAIS, J. M. Lufa-lufa quotidiana: ensaios sobre cidade, cultura e vida urbana. Lisboa: Imprensa de Ciências Sociais, 2010.

ROMANELLI, G. 0 significado da alimentação na família: uma visão antropológica. In: SIMPÓSIO TRANSTORNOS ALIMENTARES. Anorexia e bulimia nervosas. Ribeirão Preto, Cap. III, v. 39, n. 3, p. 333-339, 2006.

SANTOS, C. A alimentação e seu lugar na história: os tempos da memória gustativa. Revista da Academia Paranaense de Letras, n. 51, p. 165-188, 2005. 
SERENZUELLA, K. Ana Maria Braga fala da cozinha do "Mais Você" e da paixão por utensílios. UOL Mulher, casa e decoração, 2014. Disponivel em: <http://mulher.uol.com.br/casa-e-decoracao/ noticias/redacao/2014/02/10/ana-maria-braga-fa-

la-da-cozinha-do-mais-voce-e-da-paixao-por-utensilios.htm>. Acesso em: 26 out. 2014.

YACCOUB, H. A chamada "nova classe média": cultura material, inclusão e distinção social. Horizontes Antropológicos, Porto Alegre, v. 17, n. 36, jul./dez., p. 197-231, 2011.

ZALUAR, A. A máquina e a revolta: as organizações populares e o significado da pobreza. São Paulo: Brasiliense, 1985. 
RESUMO

Este trabalho visa compreender a relação entre mobilidade social ascendente e transformação nos hábitos de consumo alimentar, desvendando como a cozinha sujeita-se aos imperativos da moda. A adoção de determinados pratos, dietas e utensílios garante o sentimento de pertencimento à nova condição social na medida em que também se processa como ritual de afastamento da antiga. Para atingirmos nosso objetivo, recorremos a entrevistas com mulheres - tradicionalmente responsáveis pelas escolhas dos alimentos da família -, de camadas médias urbanas em Cuiabá, capital do estado de Mato Grosso, que tiveram um aumento no poder de consumo nos últimos anos. A pesquisa apontou como a mobilidade social ascendente favoreceu a inserção de alimentos/comidas considerados globalizados, como a adoção de pratos da cozinha internacional, utilização de novas tecnologias ligadas às práticas culinárias alterando o saber-fazer dessa atividade, dentre outras coisas que ressignificam as práticas alimentares e os próprios alimentos.

\section{PALAVRAS-CHAVE}

Consumo. Cultura Alimentar. Ascensão Social. Mulheres. Cuiabá.

\section{ABSTRACT}

This study aims to understand the relationship between upward social mobility and transformation in food consumption habits, revealing how the kitchen submits itself to fashion imperatives. The adoption of certain dishes, diets and utensils ensures the feeling of belonging to the new social condition and it also proceeds as the old ritual removal. To achieve our goal, we resort to interviews with women - traditionally responsible for the choices of family food - in urban middle classes in Cuiabá, the capital of Mato Grosso, who had a increase in consumption power in the last years. The research pointed out how upward social mobility favored the inclusion of foods considered globalized, the adoption of dishes from the international cuisine and the use of new technologies related to the culinary practices, changing the know-how of this activity among other things that resignify feeding practices and the food itself.

\section{KEYWORDS}

Consuption. Food culture. Social mobility. Women. Cuiabá. 
